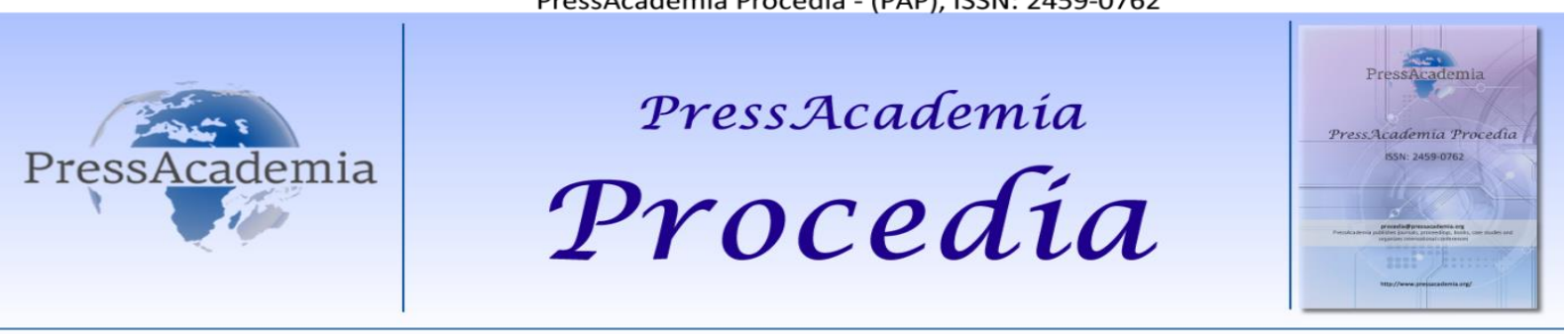

Global Business Research Congress (GBRC), May 24-25, 2017, Istanbul, Turkey

\title{
A RESEARCH ON DETERMINATION OF THE RELATIONSHIP BETWEEN RESILIENCE AND CAREER FUTURE PERCEPTION
}

DOI: 10.17261/Pressacademia.2017.631

PAP- GBRC-V.3-2017(57)-p.554-559

N. Derya Ergun Ozler ${ }^{1}$, Zehra Yeni ${ }^{2}$

${ }^{1}$ Dumlupınar Üniversitesi, ïBBF, İşletme Bölümü. deryaergun69@hotmail.com.

²Dumlupınar Üniversitesi, IỉBF, İnsan Kaynakları Yönetimi Bölümü. zehraayeni@gmail.com.

To cite this document

Ozler, N. D.E. and Z. Yeni (2017). A research on determination of the relationship between resilience and career future perception. PressAcademia Procedia (PAP), V.3, p.554-559.

Permemant link to this document: $\mathrm{http} / / /$ doi.org/10.17261/Pressacademia.2017.631

Copyright: Published by PressAcademia and limited licenced re-use rights only.

\begin{abstract}
The purpose of this study is to determine the relationship between resiliance and career future perception. First varaible is resiliance and the second varaible is career future perception which were included in the study. Resiliance consists of six dimensions. These; Selfperception, future perception, structural style, social competence, family adjustment and social resources. Career future perception consist of three dimensions. These; career adaptability, career optimism and perceived knowledge. Resiliance scale is used in research which is developed by Figor at al. in 2003-2005 and done the structure and validity study of the scale by Basım and Çetin (2011). The scale comprises 33 statements. Career future perception is a scale consisting of 25 statements. The scale is developed by Rottinghaus et al in 2005 and done the structure and validity study of the scale by Kalafat (2012). The research population is composed of 4 th grade students in Dumlupınar University, the Faculty of Economics and Administrative Sciences. Data was collected by easily sampling method. SPSS program was used for analyzing collected data. Descriptive statistics, difference tests and correlation analyzes were used to test hypotheses.

Keywords: Resiliance, Career Future Perception

JEL Codes: M12, M10, D23

\section{PSIKOLOJIK DAYANIKLILIK ILE KARIYER GELECEK ALGISI ARASINDAKI iLIŞKININ BELIRLENMESINE} YÖNELIK BIR ARAŞTIRMA
\end{abstract}

\section{ÖZET}

Bu araştırmanın temel amacı, psikolojik dayanıkııık ile kariyer gelecek algısı arasındaki ilişkiyi belirlemektir. Araştırmanın ilk değişkeni psikolojik dayanıkıılık ikinci değişkeni ise kariyer gelecek algısıdır. Psikolojik dayanıkılık; kendilik algısı, gelecek algısı, yapısal stil, sosyal yeterlilik, aile uyumu ve sosyal kaynaklar olmak üzere altı boyuttan oluşmaktadır. Kariyer gelecek algısı ise; kariyer uyumluluğu, kariyer iyimserliği ve algılanan bilgi olmak üzere üç boyuttan oluşmaktadır. Araştırmada kullanılan psikolojik dayanıklıık ölçeği Figor ve arkadaşlarını 2003-2005 yıllarına geliştirdikleri, Basım ve Çetin' in 2011 yılında yapı geçerlilik çalışmasını yaptıkları 33 ifadeli ölçektir. Kariyer gelecek algısı ölçeği ise; Rottinghaus ve arkadaşlarının 2005 yılında geliştirdikleri, 2012 yılında Kalafat' ın yapı geçerlilik çalışmasını yaptığı 25 ifadeden oluşan ölçektir. Araştırmanın evrenini Dumlupınar Üniversitesi ï̈BF' de bulunan son sınıf öğrencileri oluşturmaktadır. Kolayda örnekleme yöntemi ile veri toplanmıştır. Toplanan verilerin analizinde SPSS programından faydalanılmış ve hipotezleri test etmek amacıyla tanımlayıcı istatistik, fark testleri ve korelasyon analizleri yapılmıştır.

Anahtar Kelimeler: Psikolojik Dayanıklılık, Kariyer Gelecek Algısı.

JEL Kodları: M12, M10, D23 


\section{GíRiş}

Üniversite dönemi bireylerin bağımsız olma çabalarının devam ettiği, sorunlarla kendi başına mücadele edebilme eğiliminin yüksek olduğu, bireyler arasındaki ilişkilerin hızla değiştiği ve bireyin kendi ayakları üzerinde kalmaya başladığı bir dönemi ifade etmektedir. Bu dönem bireylerin kariyerlerine yönelik karar almaları açısından büyük önem taşımaktadır. Çünkü bu dönemde kariyere ilişkin alınacak kararlar bireyin mesleki geleceğini, sosyal kabulünü, fiziksel ve psikolojik iyi olma halini ve doğal olarak bireyin genel yaşam kalitesini ve yaşam doyumunu edoğrudan etkilemektedir. Bireyin, okulu bitince iş hayatına girmesi gerektiği düşüncesi, iş hayatına girmenin getirdiği korku, gün geçtikçe karmaşıklığı artan iş piyasaları halen öğrenciliği devam eden bireyleri endişelendirerek geleceklerine dair umutlarını azaltmaktadır.

Günümüz şartları iş dünyası için işgücü esnekliği, uyum yetenekleri ve ömür boyu öğrenmeyi gerekli kılmaktadır. Bu gerekleri; olumsuzluklar olmasına rağmen zorlukların üstesinden gelebilen, şartlar olumsuzken bile beklenenden daha iyi gelişim göstererek ayakta kalmayı başarabilen ve kişisel inançlara sahip olduğunu düşünen bireyler yerine getirebilmektedir. Bu doğrultuda iş hayatına henüz katılma aşamasında olan üniversite öğrencilerinin kariyerlerine ilişkin algılarının bireysel bir özellik olan psikolojik dayanıklııkları ile ilişkisinin olup olmadığını incelemek çalışmanın amacını oluşturmaktadır.

\section{LITERATÜR INCELEMESi}

Çalışmanın bu bölümünde araştırmanın konusunu oluşturan psikolojik dayanıklıık, kariyer gelecek algısı ve psikolojik dayanıklılık ile kariyer gelecek algısı arasındaki ilişki hakkında bilgi verilmeye çalışılacaktır.

Psikolojik dayanıklılık kavramı ilk olarak 1973 yıında Garmezy tarafından çalışılmıştır. Psikolojik dayanıklılık; bireyin yaşadığı olumsuz duygusal tecrübeler sonrasında toparlanabilmesi ve stres yaratan unsurların varlığına uyum sağlayabilme becerisi olarak ifade edilmektedir (Tugade ve Fredrickson, 2004: 320). Psikolojik dayanıklılık kavramı altı boyuttan oluşmakta ve bu boyutlar; kendilik algısı, gelecek algısı, yapısal stil, sosyal yeterlilik, aile uyumu ve sosyal kaynaklar olarak ifade edilmektedir. Friborg ve arkadaşları (2005) psikolojik dayanıklılık boyutlarını aşağıdaki şekilde ifade etmişlerdir:

$\checkmark$ Kendilik Algısı: Bireyin kendi farkındalığına vararak temelde kim olduğuna dair düşüncelerini, özgüvenini, kendisine olan sevgisini ifade etmektedir.

$\checkmark$ Gelecek Algısı: Bireyin geleceğe yönelik bakış açısını ifade etmektedir.

$\checkmark \quad$ Yapısal Stil: Bireyin güçlü yönlerini ifade etmede kullanılır ve bireysel öz disiplin, kendini planlayabilme, organize olma becerisi olarak ifade edilmektedir.

$\checkmark \quad$ Sosyal Yeterlilik: Bireyin sosyal açıdan destek görüp görmediği üzerinde durur ve bireyin sosyal ortamlara uyum sağlayabilmesi, dışa dönüklüğü ve sosyal aktivitelerde bulunma isteğini ifade etmektedir.

$\checkmark \quad$ Aile Uyumu: Bireyin ailesi ile ilişkilerini, ailesinden gördüğü desteği ve onlarla olan uyumunu ifade etmektedir,

$\checkmark$ Sosyal Kaynaklar: Bireyin çalışma arkadaşlarından ve sosyal çevresinden gördüğü desteği ifade etmektedir.

Kariyer gelecek algısı 2005 yılında Rottinghaus ve arkadaşları tarafından, Super' in (1955) çalıştığı “mesleki olgunluk kavramı" nı temel alarak geliştirdikleri bir pozitif psikoloji kavramını ifade etmektedir. Kariyer gelecek algısı; kariyer uyumluluğu, kariyer iyimserliği ve iş piyasasına ilişkin algılanan bilgi olmak üzere üç boyutu olan bir kavramı ifade etmektedir (Kalafat, 2014: 13). Rottinghaus ve arkadaşlarının (2005) kariyer gelecek algısı boyutlarını aşağıdaki şekilde sıralamak mümkündür:

$\checkmark \quad$ Kariyer Uyumluluğu: Bireyin geleceğinde karşılaşma olasılı̆̆ı olan değişimlerle başa çıkması, değişiklikler üzerinden fırsatlar oluşturması, kariyer planlamasını bu değişikliklere göre uyarlayabilmesi ve yeni sorumluluklar alarak kendini rahat hissetmesidir.

$\checkmark \quad$ Kariyer İyimserliği: Bireyin kariyeri ile ilgili gelecekte olumlu sonuçlarla karşılaşacağına dair beklentisinin olması, karşılaştığı durumlarda olayların olumlu yönlerini görebilmesi ve bireysel kariyer planlamasını yapmada rahat olmasıdır.

$\checkmark$ iş Piyasasına ilişkin Algılanan Bilgi: Bireyin gelecekte çalışmayı planladığı iş piyasasına ilişkin değişiklikleri istihdam eğilimlerini ne derece iyi algıladığıdır.

Psikolojik dayanıklılık ile kariyer gelecek algısı arasındaki ilişkiyi inceleyen araştırmalar bulunmaktadır ve yapılan araştırmalar sonucunda kariyer gelecek algısı ile psikolojik dayanıklılık arasında, kariyer gelecek algısı boyutları ile psikolojik dayanıklılık boyutları arasında ilişkilerin olduğu sonucuna ulaşılmıştır (Keleş ve Özkan, 2016, Rottinghaus vd., 2005). Psikolojik 
dayanıklılık ile kariyer gelecek algısı arasında yapılan çalışmalar iki kavramın ilişkili olduğunu göstermektedir fakat çalışmaların sonuçları uygulamasının yapıldığı, ülkeye ve meslek gruplarına göre farklılık gösterebilmektedir.

\section{VERI VE YÖNTEM}

Kariyer gelecek algısı ile psikolojik dayanıklılık arasındaki ilişkiyi belirlemeye yönelik yapılan bu çalışmanın amacı, evreni, örneklemi, kullanılan ölçekleri ve araştırmanın hipotezleri bu bölümde açıklanmıştır. Araştırmanın evrenini Dumlupınar Üniversitesi İktisadi ve İdari Bilimler Fakültesi dördüncü sınıf öğrencileri oluşturmaktadır. Dördüncü sınıf öğrencilerinin kariyerleri hakkında karar verme aşamasında oldukları düşünülerek araştırma bu evren üzerinden yürütülmüştür. Araştırmada veri toplama yöntemi olarak anket kullanılmıştır. Araştırmaya konu edilen dördüncü sınıf öğrencilerinin toplam sayısı 2923 tür. Fakültede mezun verme aşamasında olan toplam 6 bölüm bulunmaktadır. Ana kütleye toplam 750 anket formu dağıtılmış ancak zaman kısıtı nedeni ile ancak 250 anket toplanabilmiştir. Araştırmada örnekleme türü olarak olasılıklı örnekleme yöntemlerinden zümrelere göre örnekleme türü tercih edilmiştir. Bu sayede her bölümden oransal olarak öğrencinin katııımı sağlanmaya çalışımıştır. Elde edilen veriler SPSS for Windows paket programı yardımıyla araştırmanın amacının ortaya çıkarılması için istatistiki analizlere tabi tutulmuştur. Elde edilen verilerle tanımlayıcı istatistik, güvenilirlik, korelasyon yapılmış ve araştırmanın hipotezleri test edilmiştir. Araştırmada veri toplama aracı olarak anket yöntemi kullanıımıştır. Anket formu üç bölümden oluşmaktadır. İlk bölümde dördüncü sınıf öğrencilerinin demografik özelliklerine ilişkin 4 ifade, ikinci bölümde kariyer gelecek algısına yönelik 25 ifade ve son bölümde psikolojik dayanıklılığa ilişkin 33 ifade bulunmaktadır. Araştırmada kullanılan psikolojik dayanıklıık ölçeği Figor vd.' nin 2005 yılında geliştirdikleri, 33 ifadeden oluşan, 2011 yılında Basım ve Çetin' in Türkçe uyarlamasını yaptığı ölçektir. Kariyer gelecek algısı ölçeği ise; Rottinghaus vd.' nin 2005 yılında geliştirdikleri, 2012 yılında Kalafat' ın Türkçe uyarlamasını yaptığı, 25 ifadeden oluşan ölçektir. Aşağıda Şekil 1.'de psikolojik dayanıkılık ile kariyer gelecek algısı boyutları olan kariyer uyumluluğu, kariyer iyimserliği, algılanan bilgi boyutları arasındaki ilişkiyi incelemeye yönelik olarak oluşturulan araştırma modeli görülmektedir.

\section{Şekil 1: Araştırma Modeli}

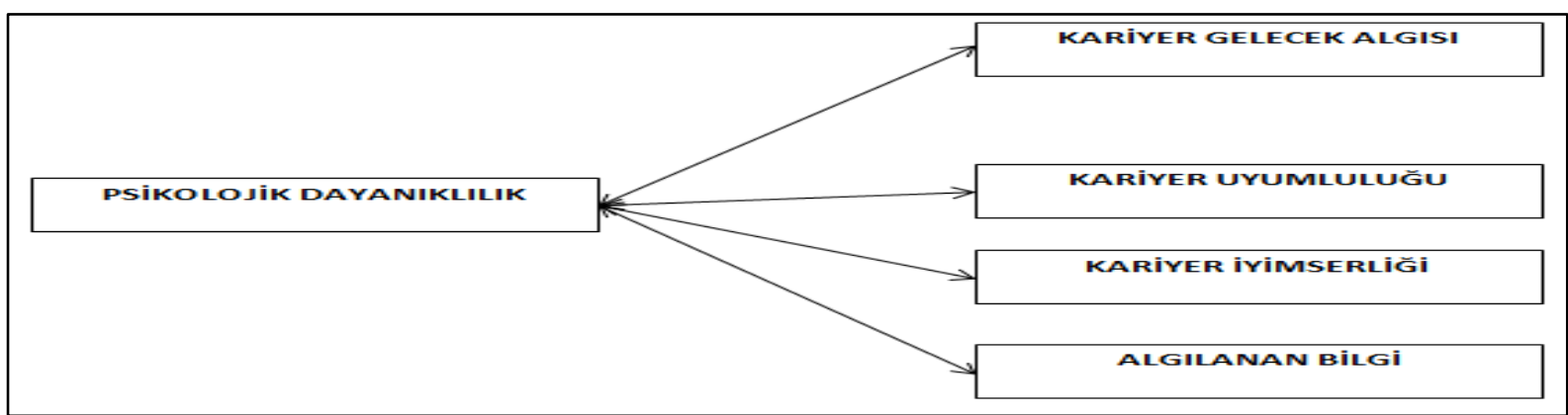

Araştırma modeli doğrultusunda kurulan hipotezler aşağıdaki gibidir:

$\mathbf{H}_{1:}$ Psikolojik dayanıklılık ile kariyer gelecek algısı arasında pozitif yönde anlamlı bir ilişki vardır.

$\mathbf{H}_{2:}$ Psikolojik dayanıklılık ile kariyer gelecek algısı boyutlarından kariyer uyumluluğu boyutu arasında pozitif yönde anlamlı bir ilişki vardır.

$\mathbf{H}_{3:}$ Psikolojik dayanıklılık ile kariyer gelecek algısı boyutlarından kariyer iyimserliği boyutu arasında pozitif yönde anlamlı bir ilişki vardır.

$\mathbf{H}_{4:}$ Psikolojik dayanıklılık ile kariyer gelecek algısı boyutlarından algılanan bilgi boyutu arasında pozitif yönde anlamlı bir ilişki vardır.

\section{BULGULAR VE TARTISSMA}

Çalışmanın bu kısmında araştırmaya konu olan örneklemin demografik özellikleri, kullanılan ölçeklere ilişkin faktör analizi, güvenilirlik analizi ve korelasyon analizi sonuçları hakkında bilgi verilmiştir. Tablo 1.'de araştırmaya konu olan örneklemin demografik özelliklerini gösteren; cinsiyet, öğrenim gördükleri bölümler ve öğretim türlerine göre dağılımları görülmektedir. 
Tablo 1: Demografik Özellikler

\begin{tabular}{|c|c|c|c|c|c|}
\hline Cinsiyet & Sayı & $\%$ & Yaş & Sayı & $\%$ \\
\hline Erkek & 84 & 33,6 & 22 ve altı & 105 & 42 \\
\hline Kadın & 112 & 66,4 & 23 ve üstü & 145 & 58 \\
\hline Toplam & 250 & 100,0 & Toplam & 250 & 100.0 \\
\hline Bölüm & Sayı & $\%$ & Gelir & Sayı & $\%$ \\
\hline Maliye & 77 & 30,8 & 1000 tl ve altı & 24 & 9,6 \\
\hline Kamu Yönetimi & 62 & 24,8 & $1001-2000 \mathrm{tl}$ arası & 87 & 38,8 \\
\hline Ekonometri & 20 & 8 & 2001-3000 tl arası & 82 & 32,8 \\
\hline İşletme & 43 & 17,2 & $3001-4000 \mathrm{tl}$ arası & 34 & 13,6 \\
\hline i̇ktisat & 48 & 19,2 & 4000 tl ve üstü & 23 & 9,2 \\
\hline Toplam & 250 & 100,0 & Toplam & 250 & 100,0 \\
\hline \multicolumn{3}{|l|}{ Öğretim } & Sayı & \multicolumn{2}{|c|}{$\%$} \\
\hline \multicolumn{3}{|l|}{ Örgün Öğretim } & 140 & \multicolumn{2}{|c|}{56} \\
\hline \multicolumn{3}{|l|}{ İkinci Öğretim } & 110 & \multicolumn{2}{|c|}{44} \\
\hline \multicolumn{3}{|l|}{ Toplam } & 250 & \multicolumn{2}{|c|}{100.0} \\
\hline
\end{tabular}

Tabloda görüldüğü gibi araştırmaya katılan öğrencilerin \% 66.4' ünü kadınlar, \% 58' ini ise 23 yaş üstü öğrenciler oluşturmaktadır. Araştırmaya katılan öğrencilerin çoğunluğunun maliye bölümü, araştırmaya katılan öğrencilerin \% $38,8^{\prime}$ inin ise ortalama aile gelirinin 1001-2000 TL arasında olduğu görülmektedir.

\begin{tabular}{|c|c|c|c|c|}
\hline $\begin{array}{l}\text { Soru } \\
\text { No: }\end{array}$ & KARIYER GELECEK ALGISI & F1 & F2 & F3 \\
\hline 2 & Gelecekte kariyer planlarımdaki değişikliklere kolayca uyum sağlayabilirim. & ,731 & & \\
\hline 3 & $\begin{array}{l}\text { Kariyer hedeflerimi gerçekleştirmede önüme çıkabilecek engellerin üstesinden } \\
\text { gelebilirim. }\end{array}$ & ,733 & & \\
\hline 4 & İşle ilgili yeni görevler almaktan keyif duyarım. & ,693 & & \\
\hline 5 & Gelecekte iş dünyasındaki değişikliklere kolayca uyum sağlayabilirim. & ,785 & & \\
\hline 6 & İş yaşamının artan taleplerine kolayca uyum sağlayabilirim. & ,651 & & \\
\hline 7 & Diğer insanlar kariyer planlarımdaki değişikliklere kolayca alışabildiğimi söyler. & ,588 & & \\
\hline 8 & Kariyerimdeki başarımı benim çabalarım belirleyecektir. & ,606 & & \\
\hline 10 & Kariyerim üzerinde çok az kontrole sahibim. & & 851 & \\
\hline 11 & Kariyerimdeki başarılar üzerinde çok az kontrole sahibim. & & ,851 & \\
\hline 12 & Kariyerim hakkında düşündüğümde heyecanlanırım. & & ,802 & \\
\hline 13 & Kariyerim hakkında düşünmek bana ilham verir. & & ,782 & \\
\hline 17 & Mesleki ilgilerimin farkındayım. & & ,757 & \\
\hline 18 & Kariyer hayallerimi takip etme konusunda oldukça azimliyim. & & & ,763 \\
\hline 23 & İş piyasasındaki eğilimleri anlamakta çok iyiyim. & & & ,757 \\
\hline 25 & Gelecekte mesleklerde meydana gelecek değişimi tahmin etmek çok kolaydır. & & & ,745 \\
\hline & $\begin{array}{l}\text { Faktörün Açıkladığı Varyans Yüzdesi: } \\
\text { Açıklanan Toplam Varyans(\%): }\end{array}$ & 23,826 & 26,250 & $\begin{array}{l}11,436 \\
61,512 \\
\end{array}$ \\
\hline & $\begin{array}{l}\text { Testler } \\
\text { Kaiser-Meyer-Olkin test (KMO): , } 817 \\
\text { Bartlett's Test of Sphericity: 1210,690 }(P<, 000)\end{array}$ & & & \\
\hline
\end{tabular}

Kariyer gelecek algısına yönelik faktör analizi sonuçları tablo 2.'de görülmektedir. Kariyer gelecek algısı ölçeği için varimax işlemi uygulanmıştır. Ölçekteki Faktör sayısı üçtür ve bu faktörlerin toplam varyansı açıklama oranı \% 61,512 dir. Ölçekte bulunan ifade sayısı 25 olmasına rağmen 1,9,14,19,21,22 nolu ifadeler herhangi bir boyuta yerleşememe nedeni ile, 15,16,20 nolu ifadeler tek başına kalma nedeni ile ve 24 nolu ifade birden fazla faktöre yerleşmesi nedeni ile analiz dışı bırakılmıştır. Ortaya çıkan bu faktörleri oluşturan alt bileşenler ve faktör yapılarına bakıldığında, yedi soruyu içeren ilk faktör (F1), kariyer uyumluluğu boyutunu oluşturmaktadır. Diğer 5 ifadenin oluşturduğu faktör (F2) ise kariyer iyimserliğidir. Son faktörü (F3) oluşturan 3 ifade ise iş piyasasına ilişkin algılanan bilgiyi ifade etmektedir. Bununla birlikte, örneklem yeterliliğini gösteren Kaiser-Meyer-Olkin (KMO) değeri $(, 817)$ araştırmanın yapılmasında uygun kabul edilen sınırlar arasında 
yer almaktadır. Verilerin çoklu normal dağılımdan geldiğini gösteren Barlett Testi' nde kabul edilen sınırlar içerisinde yer almaktadır ( $p<, 000$ ). Bu bulgular, elde edilen faktörlerin araştırmada kullanılmasında herhangi bir uygunsuzluğun olmadığını göstermektedir.

Tablo 3: Ölçeklerin Güvenilirlik Analizi

\begin{tabular}{|l|c|c|}
\hline ÖLÇEKLER & $\begin{array}{c}\text { SORU } \\
\text { SAYISI }\end{array}$ & $\begin{array}{c}\text { ALFA } \\
\text { KATSAYILARI( } \boldsymbol{\alpha})\end{array}$ \\
\hline Psikolojik Dayanıklılık & 33 &, 84 \\
\hline Kariyer Gelecek AlgıIı & 15 &, 73 \\
\hline Kariyer Uyumluluğu & 7 &, 83 \\
\hline Kariyer İyimserliği & 5 &, 61 \\
\hline Algılanan Bilgi & 3 &, 53 \\
\hline Genel Toplam & $\mathbf{4 8}$ & $\mathbf{8 5}$ \\
\hline
\end{tabular}

Araştırmada kullanılan ölçeklere ilişkin güvenilirlik analizleri sonuçları tablo 3'te görülmektedir. Ölçeklerin güvenilirlik düzeyleri \% 53 ile \% 84 arasında değişmektedir. Bu sonuçlar araştırmanın yapılması için gerekli sınırlar arasında yer almaktadır. Korelasyon analizi sonuçlarına göre araştırmaya konu olan değişkenler arasındaki ilişki incelenmiştir. Değişkenlerin arasında $(p<0,01)$ ve $(p<0,05)$ anlam düzeylerinde çift yönlü ilişkilerin olduğu, değişkenlerin bazılarının arasında ise istatistiksel olarak anlamlı bir ilişkinin olmadığı $(p>0,05)$ tespit edilmiştir.

Tablo 4: Korelasyon Analizi Sonuçları

\begin{tabular}{|l|l|l|l|l|l|}
\hline Değişkenler & $\begin{array}{l}\text { Psikolojik } \\
\text { Dayanıkııık }\end{array}$ & $\begin{array}{l}\text { Kariyer Gelecek } \\
\text { Algısı }\end{array}$ & $\begin{array}{l}\text { Kariyer } \\
\text { Uyumluluğu }\end{array}$ & Kariyer İyimserliği & Algılanan Bilgi \\
\hline $\begin{array}{l}\text { Psikolojik } \\
\text { Dayanıkılık }\end{array}$ & $\mathbf{1}$ &, $289^{* *}$ &, $327^{* *}$ &,-151 &, $292^{* *}$ \\
\hline $\begin{array}{l}\text { Kariyer } \\
\text { Gelecek } \\
\text { Algısı }\end{array}$ & $\mathbf{1}$ &, $851^{* *}$ &, $611^{* *}$ &, $584^{* *}$ \\
\hline $\begin{array}{l}\text { Kariyer } \\
\text { Uyumluluğu }\end{array}$ & & 1 &, $207^{* *}$ &, $290^{* *}$ \\
\hline $\begin{array}{l}\text { Kariyer } \\
\text { Iyimserliği }\end{array}$ & & & 1 & &, $221^{* *}$ \\
\hline $\begin{array}{l}\text { Algılanan } \\
\text { Bilgi }\end{array}$ & & & & 1 \\
\hline
\end{tabular}

**,01 seviyesinde anlamlı (çift tarafı)

Yapılan korelasyon analizleri sonucunda değişkenler arasında anlamlı ilişkiler olduğu tespit edilmiştir. Tablo 4'e bakıldığında psikolojik dayanıklılık ile kariyer gelecek algısı arasında pozitif yönlü ve anlamlı ilişkilerin olduğu görülmektedir. Bu sonuca göre " $H_{1}$ : Psikolojik dayanıklıık ile kariyer gelecek algısı arasında pozitif yönde anlamlı bir ilişki vardır" hipotezi kabul edilmiştir. Yani; iktisadi ve idari bilimler fakültesi dördüncü sınıf öğrencilerinin psikolojik dayanıklılıkları ile kariyer gelecek algıları arasında pozitif yönlü anlamlı ilişkilerin olduğunu söylemek mümkündür.

Yapılan korelasyon analizi sonuçlarına göre psikolojik dayanıklılık ile kariyer gelecek algısı boyutlarından kariyer uyumluluğu ve algılanan bilgi boyutları arasında pozitif yönlü ve anlamlı ilişkilerin olduğu tespit edilmiştir. Fakat psikolojik dayanıklılık ile kariyer gelecek algısı boyutlarından kariyer iyimserliği boyutu arasında anlamlı bir ilişki tespit edilmemiştir. Bu sonuca göre " $H_{2:}$ Psikolojik dayanıklılık ile kariyer gelecek algısı boyutlarından kariyer uyumluluğu boyutu arasında pozitif yönde anlamlı bir ilişki vardır" hipotezi ve " $\mathrm{H}_{4:}$ Psikolojik dayanıklıık ile kariyer gelecek algısı boyutlarından algılanan bilgi boyutu arasında pozitif yönde anlamlı bir ilişki vardır" hipotezi kabul edilmiş, " $H_{3}$. Psikolojik dayanıklılık ile kariyer gelecek algısı boyutlarından kariyer iyimserliği boyutu arasında pozitif yönde anlamlı bir ilişki vardır" hipotezi ise reddedilmiştir.

Özetle; İktisadi ve idari bilimler fakültesi dördüncü sınıf öğrencilerinin psikolojik dayanıklııkları ile kariyerlerine ilişkin ortaya çıkacak olumsuz veya olumlu şartlara uyum sağlayacakları ve ileride kariyerlerini planladıkları iş piyasası hakkında ortaya çıkan değişiklikler hakkında bilgiyi takip ederek algıladıkları söylenebilir. Buna ek olarak; İktisadi ve idari bilimler fakültesi dördüncü sınıf öğrencilerinin psikolojik dayanıklıııkarı ile ulaşmayı planladıkları kariyer hedefine ilişkin ümitli olmadıkları nı ifade etmek mümkündür. 


\section{SONUÇ}

Bu çalışma psikolojik dayanıklılık ile kariyer gelecek algısı arasındaki ilişkiyi tespit etmek amacıyla yapılmıştır. Çalışmada ilk olarak psikolojik dayanıklılık ve kariyer gelecek algısı hakkında bilgi verilmeye çalışılmıştır. Sonrasında araştırmanın veri ve yöntemiüzerinde durularak, araştırmanın hangi veri toplama araçları ile hangi analizlere tabi tutulduğu ile araştırmanın hipotezleri ve modeline yönelik bilgi verilmiştir. Günümüzdeki rekabet, siyasi, ekonomik ve psikolojik faktörler gözönünde bulundurulduğunda, iş hayatına henüz katılma planları içinde olan son sınıf üniversite öğrencilerinin psikolojik dayanıklılık düzeylerinin önemli olduğu düşünülmektedir. Bu nedenle üniversite öğrencilerinin kendilerini geleceğe hazırlamaları, yeteneklerini geliştirici faaliyetlerde bulunmaları, aile ve sosyal desteği yanlarında bulundurarak bireysel yetkinliklerini geliştirmek için destek almaları gerekmektedir. Öğrencilik aşamasında bireysel kariyer planlamasını yapmak için kendi yeteneklerini geliştirici faaliyetlerde bulunan bireylerin psikolojik dayanıklılık düzeyleri yüksek olacak ve bu durum kariyerlerine olumlu yönde etki edecektir.

Bu çalışma Dumlupınar Üniversitesi İktisadi ve İdari Bilimler Fakültesi dördüncü sınıf öğrencileri üzerinde yapılmıştır. Çalışmanın dördüncü sınıf öğrencileri üzerinde yapılma nedeni iş yaşamına henüz atılma aşamasında olmaları, ileride planladıkları meslek hakkında karar verme aşamasında ve meslek grupları hakkında bilgi sahibi olmalarıdır. Araştırmanın hipotezleri korelasyon analizi ile test edilmiştir. Bu analiz yönteminin kullanılması psikolojik dayanıklılık ile kariyer gelecek algısı arasındaki ilişkinin tespit edilmesi için uygun ve yeterli görülmüştür. Analiz sonuçlarına göre psikolojik dayanıklıık ile kariyer gelecek algısı arasında pozitif yönlü anlamlı ilişkilerin olduğu sonucuna ulaşılmıştır. Psikolojik dayanıklılık ile kariyer gelecek algısı boyutlarından kariyer uyumluluğu ve algılanan bilgi boyutları arasında da pozitif yönlü ve anlamlı ilişkiler tespit edilmiştir fakat psikolojik dayanıklılık ile kariyer gelecek algısı boyutlarından kariyer iyimserliği boyutu arasında herhangi bir anlamlı ilişkiye rastlanmamıştır.

Yani üniversite öğrencilerinin psikolojik dayanıklılı̆ı ile kariyer gelecek algıları arasında ilişki vardır ve üniversite öğrencilerinin psikolojik dayanıkıı̆ı̆ı ile kariyerlerini planladıkları çevrenin şartlarına uyum sağlama kabiliyetleri, ileride olmak istedikleri meslek hakkında iş piyasasında ortaya çıkan bilgiyi algılamaları arasında anlamlı bir ilişkinin olduğu tespit edilmiştir. Buna ek olarak üniversite öğrencilerinin psikolojik dayanıklıı̆̆ı ile kariyerleri için planladıkları hedefi hayata geçirmeye dair olan beklenti ve ümitleri arasında bir ilişkinin olmadığı da tespit edilmiştir. Psikolojik dayanıklılık konusunun yönetim ve organizasyon alanına psikoloji biliminden gelmiş bir kavram olması sebebiyle birçok örgütsel davranış konusu ile çalışılması mümkündür. Fakat özellikle olumsuz örgütsel davranış konularının tercih edilmesinin, anlamlı sonuçların çıkması açısından ve sonuçlarının olumsuz davranışların ortadan kaldırılmasına yardımcı olması açısından faydalı olacağı düşünülmektedir. Kariyer gelecek algısı insan kaynakları yönetimi bilimine ait olan güncel kavramlardan birini oluşturmaktadır. Kariyer gelecek algısı kavramının da örgütsel davranış kavramları ile çalışılarak geliştirilmesi disiplinler arası

\section{KAYNAKLAR}

Basım, H. N. ve Çetin, F., (2011). Yetişkinler İçin Psikolojik Dayanıklılık Ölçeğinin Güvenilirlik ve Geçerlilik Çalışması. Türk Psikiyatri Dergisi, Cilt. 22, Sayı. 2, s. 104-114.

Friborg, O., Barlaug, D., Martinussen, M., Rosenvinge, J.H. and Hjemdal. (2005). Resilience in Relation to Personality and Intelligence. Int J Methods Psychiatr Res, vol. 14, no. 1, p. 29-42.

Kalafat, T., (2012). Kariyer Geleceği Ölçeği (KARGEL): Türk Örneklemi İçin Psikometrik Özelliklerinin İncelenmesi. Türk Psikolojik Danışma ve Rehberlik Dergisi. vol. 4, no. 38. p. 169-179.

Kalafat, T., (2014). Kariyer Gelecek Algııını Etkileyen Kişisel Faktörlerin Belirlenmesine Yönelik Bir Model Çalışması. Ankara Üniversitesi Eğitim Bilimleri Enstitüsü (Yayınlanmamış Doktora Tezi). Ankara.

Keleş, H.N.ve Özkan, T.K., (2016). Kariyer Gelecek Algısının Psikolojik Dayanıkıılık Değişkenine Göre İncelenmesi. IV. Örgütsel Davranış Kongresi Bildiriler Kitapçı̆ı. Adana Çukurova Üniversitesi. ss. 180-186.

Rottinghaus, P.J., Day, S.X., and Borgen, F.H., (2005). The Career Futures Inventory: A Measure Of Careerrelated Adaptability And Optimism. Journal of Career Assessment. vol. 13, no. 1, p. 3-24.

Tugade, M. M., ve B. L. Fredrickson. (2004). Resilient Individuals Use Positive Emotions to Bounce Back From Negative Emotional Experiences. Journal of Personality and Social Psychology. 86, 320-333. 